\title{
Prevalence of Hypertension in a Tribal Land Locked Population at High Altitude
}

\author{
Sunil Kumar Raina, ${ }^{1}$ Vishav Chander, ${ }^{1}$ Chaman Lal Prasher, ${ }^{1}$ and Sujeet Raina ${ }^{2}$ \\ ${ }^{1}$ Community Medicine, Dr. Rajendra Prasad Government Medical College, Tanda 176001, India \\ ${ }^{2}$ Internal Medicine, Dr. Rajendra Prasad Government Medical College, Tanda 176001, India \\ Correspondence should be addressed to Sunil Kumar Raina; ojasrainasunil@yahoo.co.in
}

Received 19 December 2015; Revised 21 January 2016; Accepted 24 January 2016

Academic Editor: Yaron Arbel

Copyright (c) 2016 Sunil Kumar Raina et al. This is an open access article distributed under the Creative Commons Attribution License, which permits unrestricted use, distribution, and reproduction in any medium, provided the original work is properly cited.

\begin{abstract}
Introduction. Extensive pubmed search reveals paucity of data on prevalence of hypertension in tribal population at high altitude. The data is all the more scarce from our part of India. Studies among tribal populations at high altitudes provide an interesting epidemiological window to study human evolution and adaptation to hypobaric hypoxia. Material and Methods. 401 participants above the age of 20 years were evaluated for blood pressure using a stratified simple random technique among villages located at high altitude. Results. Out of a total of 401 individuals studied 43 (males: 35; females: 8) were identified as hypertensive yielding a crude prevalence of $10.7 \%$. The prevalence was higher in males $(35 / 270 ; 12.9 \%)$ as compared to females $(8 / 131 ; 6 \%)$. Prevalence was the highest in the age group of $30-39$ among males $(16 / 35 ; 45.7 \%)$ while it was the highest in the age group of $40-49$ among females (7/8; $87 \%)$. Conclusions. Prevalence of $10.5 \%$ is noteworthy when interpreted in light of prevalence of hypertension in general population especially if hypobaric hypoxia is considered to have a protective effect on blood pressure in high altitude native populations.
\end{abstract}

\section{Introduction}

An extensive pubmed search reveals paucity of data on prevalence of hypertension in tribal population at high altitude. The data is all the more scarce from our part of India. A few studies in this regard reveal contradictory views on the prevalence of hypertension among populations at high altitude. This contradiction in prevalence is even reflected in two studies conducted in Spiti valley $(4000 \mathrm{~m})$ of Himachal Pradesh state, although the reason for difference in prevalence at Spiti could partly be attributed to the difference in cut-off used for defining hypertension [1]. Similar to this, studies conducted among high altitude natives of Andes [25], Pamirs and Tienshan [6], Amaras region of Ethiopia [7], Sherpas of Nepal [8], Tibetans of India [9], and rural high altitude natives in Greater Himalayas [10] have shown BP values of natives to be lower than the residents of plains and low altitude. However, studies among Tibetans of Lhasa [11], high altitude natives of Saudi Arabia [12], high altitude natives of Ethiopia [13], and high altitude cold zone cattle-breeders of Mongolia [14] have also shown opposite results.
In health and diseases research, tribal populations at high altitude provide an interesting epidemiological window to study human evolution and adaptation to hypobaric hypoxia.

Civilizations with longest history of ancestry (tribal populations living at high altitude) are likely to be genetically more adapted than ones with shorter history of ancestry to natural stressors. It is supposed that the natives of Tibetan plateau of Himalayan region have longer history of ancestry than civilizations in other mountainous regions [15]. The course of evolution and adaptation may have modified many of the human physiological processes, blood pressure being one of them.

\section{Material \& Methods}

2.1. Background. Pangi valley is a remote, rugged, and poorly developed tribal area in Himachal Pradesh state. Pangi valley is divided into Saichu, Hudan Bhatori, Chasak Batori, and Sural Bhatori valleys [16]. These are inhabited at elevations of 7,000 feet $(2,100 \mathrm{~m})$ to 12,000 feet $(4000 \mathrm{~m})$ above sea level. 
Roads are poor, with few of them surfaced. The entry to the valley is through the Saach Pass. The valley is approachable only between July end and October through Saach Pass, which remains closed by heavy snow at other times of the year.

The Pangi tehsil covers 1,601 square kilometres (618 sq mi) and had a population of 17,598 at the 2001 census. Pangi has 16 panchayats and 54 inhabited villages.

The major tribes inhabiting this area are Pangwals, Lahaula, and Bhot or Bodh. They belong to different castes. The inhabitants of Pangi originally seem to have converged on Pangi from various quarters but the seclusion and inaccessibility forced by geography have wedded these castes into a single tribal community. The villages of Pangi have seen least of in-migration and are almost entirely inhabited by local tribals [16].

The staple food in Pangi is barley, elo (rye), wheat, buckwheat, suil, and chana (both inferior kinds of millets). The wheat and rice are supplied by the government. Further certain grasses and roots like Kangash and Chukri are also consumed. Mutton is often eaten in the winters and on special occasions. Potato is also an important component of diet [16].

Barley, elo, phullan, and bres (buckwheat) and to a small extent wheat are ground into meal for bread which is baked into various forms. Moreover, suil, elo, and barely are parched into ground into flour, called Sattu, and eaten without cooking either with buttermilk, water, or tea. Walnut oil and ghee are used mainly for frying vegetables and pulses. People take meals thrice a day. Villagers in Pangi use liquor extensively. This liquor is mostly brewed locally. In addition to liquor, tea, prepared from tea leaves purchased from market and Choga (tea made from local plant species), is also consumed. Choga is prepared by boiling water, milk, salt, and Choga leaves [16].

\subsection{Methods}

2.2.1. Study Participants. Assuming a prevalence of $5 \%$ with target population of around 5000 from the study area (the high altitude values), required sample size calculated was 377 at $99.9 \%$ CI. All individuals aged 20 years and above from Pangi were the target population screened. A stratified simple random technique was used to include participants for this study. All the villages from Sural Batori valley (10,000 feet; 3048 meters) and Chasak Batori valley (12,000 feet; 3658 meters) were stratified to 2 groups of villages. Villages from each group were selected using random number table so that about 250 eligible individuals could be selected from each of the 2 altitude groups. A higher number was chosen to account for nonwillingness of individuals to participate in the study. A total of 401 individuals participated in the study giving us a response rate of $90 \%$.

2.2.2. Study Design. A total of 401 participants aged above 20 years were included in this study.

A two-stage stratified sampling design was used to select a representative sample of the adult population over 20 years of age. The occupation was interviewed from all the participants and classified into four groups: agriculturists, government service, private services, shopkeeper/business, retired from service, and others (housewife, manual labourer, monk, and with no job). Only a full-time housewife was regarded as a housewife while a housewife who also worked as an agriculturist was classified as agriculturist. Further each study participant was interviewed to record information pertaining to history of being aware of having hypertension, record of blood pressure, being aware of having diabetes, and history of tobacco and alcohol consumption.

Anthropometric measurements including weight and height were obtained using standard techniques. Height was recorded with the help of a stadiometer to the nearest of $5 \mathrm{~mm}$. Weight was measured by a digital weighing machine to the nearest $100 \mathrm{~g}$ and was calibrated using standard weight every day.

The body mass index (BMI) was calculated using the formula, weight $(\mathrm{kg}) /(\text { height }(\mathrm{m}))^{2}$. BMI $\geq 23 \mathrm{~kg} / \mathrm{m}^{2}$ was defined as overweight. Blood pressure was measured using an automatic device (HEM 7000; OMRON Life Science Co. Ltd., Kyoto, Japan). Blood pressure was measured twice after taking at least a 5 min rest in a sitting position and the mean of systolic blood pressure (SBP) and diastolic blood pressure (DBP) was calculated. SBP $\geq 140 \mathrm{~mm} \mathrm{Hg}$ and/or DBP of $\geq 90 \mathrm{~mm} \mathrm{Hg}$ and/or taking current antihypertensive medicine was defined as hypertension.

\section{Results}

A total of 401 (males: 270; 67.3\% and females: 131; 32.7\%) participants aged between 20 and 94 years were included in the study. Majority (61\%) of the participants belonged to age group of 30-49. The details are provided in Table 1. This table also provides us with details on the prevalence of hypertension. Out of a total of 401 individuals studied 43 (male: 35; female 8) were identified as hypertensive yielding a crude prevalence of $10.7 \%$. The prevalence was higher in males $(35 / 270 ; 12.9 \%)$ as compared to females $(8 / 131 ; 6 \%)$. Prevalence was the highest in the age group of 30-39 among males $(16 / 35 ; 45.7 \%)$ while it was the highest in the age group of 40-49 among females (7/8; 87\%).

Table 2 shows the characteristics of all variables of the study participants. Smoking is seen to be common in males with more than $50 \%$ reporting as current smoker, occasional smoker, or ex-smoker. Interestingly $9.2 \%$ of females also were reported as current smoker. Use of alcohol was reported by a majority (69\%) of male participants compared to only $0.8 \%$ females. The maximum number of participants was illiterate (males: 20\%; females: 61.8\%).

Table 3 provides details on mean and median of height, weight, body mass Index (BMI), systolic blood pressure (SBP), and diastolic blood pressure (DBP) according to gender of the study participants. The mean and the median BMI for both male and female gender is within normal limits with little difference between the two (males: $20.80 \pm 2.73$, 20.68; females: $20.41 \pm 2.42$; 19.56).

The mean and median SBP for males is $124.56 \pm 17.44$ and 124 while for females it is $115.82 \pm 14.03$ and 115 , respectively. The mean DBP for males is $76.68 \pm 10.45$ and 76 while for females it is $73.31 \pm 8.83$ and 73 , respectively. The mean and 
TABLE 1: Demographic profile of study participants and prevalence of hypertension among study participants.

\begin{tabular}{|c|c|c|c|c|c|c|c|c|c|c|c|c|}
\hline \multirow[t]{2}{*}{$\begin{array}{l}\text { Age group } \\
\text { (years) }\end{array}$} & \multicolumn{3}{|c|}{ Number (\%) } & \multicolumn{3}{|c|}{ Mean age (SD) } & \multicolumn{3}{|c|}{$\begin{array}{c}\text { Hypertensive } \\
n(\%)\end{array}$} & \multicolumn{3}{|c|}{$\begin{array}{c}\text { Nonhypertensive } \\
n(\%)\end{array}$} \\
\hline & Male & Female & Total & Male & Female & Total & Male & Female & Total & Male & Female & Total \\
\hline $20-29$ & $\begin{array}{c}56 \\
(14.0)\end{array}$ & $17(4.2)$ & $\begin{array}{c}73 \\
(18.2)\end{array}$ & $\begin{array}{l}24.89 \\
(2.77)\end{array}$ & $\begin{array}{l}25.76 \\
(2.61)\end{array}$ & $\begin{array}{l}25.10 \\
(2.74)\end{array}$ & $1(0.2)$ & - & $1(0.2)$ & $55(13.7)$ & $17(2.61)$ & $\begin{array}{c}72 \\
(18.0)\end{array}$ \\
\hline $30-39$ & $\begin{array}{c}82 \\
(20.4)\end{array}$ & $\begin{array}{c}60 \\
(15.0)\end{array}$ & $\begin{array}{c}142 \\
(35.4)\end{array}$ & $\begin{array}{l}33.66 \\
(3.03)\end{array}$ & $\begin{array}{l}34.45 \\
(3.72)\end{array}$ & $\begin{array}{l}33.99 \\
(3.35)\end{array}$ & $\begin{array}{c}16 \\
(4.0)\end{array}$ & - & $\begin{array}{c}16 \\
(4.0)\end{array}$ & $\begin{array}{c}66 \\
(16.5)\end{array}$ & $\begin{array}{c}60 \\
(15.0)\end{array}$ & $\begin{array}{c}126 \\
(31.4)\end{array}$ \\
\hline $40-49$ & $\begin{array}{c}76 \\
(19.0)\end{array}$ & $27(6.7)$ & $\begin{array}{c}103 \\
(25.7)\end{array}$ & $\begin{array}{l}44.16 \\
(2.45)\end{array}$ & $\begin{array}{l}44.37 \\
(3.34)\end{array}$ & $\begin{array}{l}44.21 \\
(2.70)\end{array}$ & $8(2.0)$ & $7(1.7)$ & $\begin{array}{c}15 \\
(3.7)\end{array}$ & $68(17.0)$ & $20(5.0)$ & $\begin{array}{c}88 \\
(21.9)\end{array}$ \\
\hline $50-59$ & $\begin{array}{c}30 \\
(7.5)\end{array}$ & $16(4.0)$ & $\begin{array}{c}46 \\
(11.5)\end{array}$ & $\begin{array}{l}55.50 \\
(2.56)\end{array}$ & $\begin{array}{l}53.69 \\
(2.82)\end{array}$ & $\begin{array}{l}54.87 \\
(2.76)\end{array}$ & $3(0.7)$ & $1(0.2)$ & $4(1.0)$ & $27(6.7)$ & $15(3.7)$ & $\begin{array}{c}42 \\
(10.5)\end{array}$ \\
\hline$\geq 60$ & $\begin{array}{c}26 \\
(6.5) \\
\end{array}$ & $11(2.7)$ & $\begin{array}{c}37 \\
(9.2) \\
\end{array}$ & $\begin{array}{l}64.54 \\
(5.83) \\
\end{array}$ & $\begin{array}{r}65.55 \\
(4.43) \\
\end{array}$ & $\begin{array}{l}64.84 \\
(5.41) \\
\end{array}$ & $7(1.7)$ & - & $7(1.7)$ & $19(4.7)$ & $11(2.7)$ & $\begin{array}{c}30 \\
(7.5) \\
\end{array}$ \\
\hline Total & $\begin{array}{c}270 \\
(67.3)\end{array}$ & $\begin{array}{c}131 \\
(32.7)\end{array}$ & $\begin{array}{c}401 \\
(100.0)\end{array}$ & $\begin{array}{c}40.19 \\
(12.64)\end{array}$ & $\begin{array}{c}40.33 \\
(11.60)\end{array}$ & $\begin{array}{c}40.23 \\
(12.30)\end{array}$ & $\begin{array}{c}35 \\
(8.7)\end{array}$ & $8(2.0)$ & $\begin{array}{c}43 \\
(10.7)\end{array}$ & $\begin{array}{c}235 \\
(58.6)\end{array}$ & $\begin{array}{c}123 \\
(30.7)\end{array}$ & $\begin{array}{c}358 \\
(89.3)\end{array}$ \\
\hline
\end{tabular}

TABLE 2: Frequency distribution of different variables among study participants.

\begin{tabular}{|c|c|c|c|c|}
\hline Characteristic & $\begin{array}{l}\text { Male } \\
n(\%)\end{array}$ & $\begin{array}{c}\text { Female } \\
n(\%)\end{array}$ & Mean systolic $\mathrm{BP} \pm \mathrm{SD}$ & Mean diastolic $\mathrm{BP} \pm \mathrm{SD}$ \\
\hline \multicolumn{5}{|l|}{ Smoking habits } \\
\hline Smoker & $115(42.6)$ & $12(9.2)$ & $121.08 \pm 17.47$ & $74.03 \pm 9.61$ \\
\hline Occasional smoker & $7(2.6)$ & - & $143.71 \pm 24.58$ & $88.57 \pm 5.47$ \\
\hline Ex-smoker & $15(5.5)$ & - & $113.60 \pm 7.25$ & $71.20 \pm 6.80$ \\
\hline Nonsmoker & $133(42.3)$ & $119(90.8)$ & $121.89 \pm 16.33$ & $76.26 \pm 10.21$ \\
\hline \multicolumn{5}{|l|}{ Alcohol consumption } \\
\hline Alcoholic & $159(58.9)$ & $1(0.8)$ & $123.62 \pm 18.13$ & $76.59 \pm 10.77$ \\
\hline Occasional alcoholic & $26(9.6)$ & - & $123.96 \pm 7.72$ & $75.50 \pm 8.92$ \\
\hline Nonalcoholic & $85(31.5)$ & $130(99.2)$ & $120.01 \pm 16.62$ & $74.84 \pm 9.63$ \\
\hline \multicolumn{5}{|l|}{ Educational status } \\
\hline Illiterate & $54(20.0)$ & $81(61.8)$ & $119.71 \pm 19.28$ & $73.33 \pm 7.65$ \\
\hline Primary school & $34(12.6)$ & $15(11.4)$ & $110.02 \pm 13.69$ & $68.55 \pm 8.24$ \\
\hline High school not completed & $50(18.5)$ & $10(7.6)$ & $121.13 \pm 11.12$ & $75.10 \pm 9.26$ \\
\hline High school & $32(11.8)$ & $1(0.8)$ & $124.67 \pm 11.05$ & $77.97 \pm 9.12$ \\
\hline Secondary school & $43(15.9)$ & $10(7.6)$ & $125.57 \pm 12.27$ & $81.55 \pm 10.94$ \\
\hline Graduate & $18(6.7)$ & - & $123.56 \pm 12.99$ & $79.61 \pm 9.58$ \\
\hline Postgraduate/professional degree & $24(8.9)$ & $14(10.8)$ & $137.68 \pm 19.63$ & $84.55 \pm 10.46$ \\
\hline Others & $15(5.6)$ & - & $117.27 \pm 7.52$ & $66.73 \pm 3.39$ \\
\hline \multicolumn{5}{|l|}{ Occupation } \\
\hline Agriculture & $119(44.1)$ & $46(35.1)$ & $122.22 \pm 17.26$ & $75.33 \pm 9.31$ \\
\hline Government service & $77(28.5)$ & $23(17.5)$ & $124.95 \pm 17.82$ & $77.80 \pm 10.86$ \\
\hline Private service & $9(3.3)$ & $6(4.6)$ & $130.60 \pm 18.29$ & $83.53 \pm 13.53$ \\
\hline Shopkeeper/business & $20(7.4)$ & $12(9.2)$ & $118.22 \pm 13.33$ & $73.84 \pm 9.19$ \\
\hline Retired & $3(1.1)$ & - & $116.33 \pm 16.77$ & $68.67 \pm 6.35$ \\
\hline Others & $42(15.6)$ & $44(33.6)$ & $116.87 \pm 14.69$ & $72.97 \pm 9.14$ \\
\hline
\end{tabular}


TABLE 3: Anthropometric characteristics of study participants.

\begin{tabular}{|c|c|c|c|}
\hline & Mean \pm SD & Median & $\begin{array}{c}95 \% \text { confidence } \\
\text { interval }\end{array}$ \\
\hline \multicolumn{4}{|c|}{ Height (meters) } \\
\hline Male & $1.65 \pm 0.05$ & 1.65 & $1.64-1.65$ \\
\hline Female & $1.57 \pm 0.04$ & 1.57 & $1.56-1.57$ \\
\hline Total & $1.62 \pm 0.06$ & 1.62 & $1.62-1.63$ \\
\hline \multicolumn{4}{|c|}{$\begin{array}{l}\text { Weight } \\
\text { (kilograms) }\end{array}$} \\
\hline Male & $56.26 \pm 7.51$ & 56.00 & $55.36-57.16$ \\
\hline Female & $50.32 \pm 7.02$ & 48.60 & $49.10-51.53$ \\
\hline Total & $54.32 \pm 7.86$ & 53.00 & $53.55-55.09$ \\
\hline \multicolumn{4}{|c|}{$\begin{array}{l}\text { Body mass } \\
\text { index } \\
(\text { kilograms/m²) }\end{array}$} \\
\hline Male & $20.80 \pm 2.73$ & 20.68 & $20.47-21.13$ \\
\hline Female & $20.41 \pm 2.42$ & 19.56 & $19.99-20.83$ \\
\hline Total & $20.67 \pm 2.64$ & 20.44 & $20.41-20.93$ \\
\hline \multicolumn{4}{|c|}{$\begin{array}{l}\text { Systolic blood } \\
\text { pressure (mm of } \\
\mathrm{Hg})\end{array}$} \\
\hline Male & $124.56 \pm 17.44$ & 124.00 & $122.47-126.65$ \\
\hline Female & $115.82 \pm 14.03$ & 115.00 & $113.39-118.24$ \\
\hline Total & $121.71 \pm 16.89$ & 120.00 & $120.05-123.36$ \\
\hline \multicolumn{4}{|c|}{$\begin{array}{l}\text { Diastolic blood } \\
\text { pressure ( } \mathrm{mm} \text { of } \\
\mathrm{Hg})\end{array}$} \\
\hline Male & $76.68 \pm 10.45$ & 76.00 & $75.43-77.93$ \\
\hline Female & $73.31 \pm 8.83$ & 73.00 & $71.79-74.84$ \\
\hline Total & $75.58 \pm 10.07$ & 75.00 & $74.59-76.57$ \\
\hline
\end{tabular}

median population SBP for residents of Pangi is $121 \pm 16.89$ and 120 , respectively. The mean and median population DBP for residents of Pangi is $75.58 \pm 10.07$ and 75, respectively.

Table 4 reports on awareness of study participants about their status of blood pressure and blood sugar. A large proportion of males (215/270: 80\%) and females (116/131: $88.5 \%$ ) reported not having got examined for raised blood pressure in the last 5 years.

Figure 1 reports on the corelation of SBP and DBP with age and body mass index (BMI). It is observed that as the age increases both SBP and DBP raise. Similarly as the BMI rises both SBP and DBP rise. However, the correlation coefficient was found to be not significant for age and diastolic blood pressure (DBP) pointing to constancy in DBP with age. Figure 2 reports on the corelation of SBP and DBP with smoking and alcohol. It is observed that SBP and DBP rise with smoking while no such relation is observed with alcohol. However, the correlation coefficients for both smoking and alcohol are not significant. Figure 3 reports on the corelation of SBP and DBP with age among males. There is no significant increase in blood pressure with age among males. The lack of
TABLE 4: Awareness regarding blood pressure among study participants.

\begin{tabular}{lccc}
\hline \multirow{2}{*}{ Question } & \multicolumn{3}{c}{ Number (\%) } \\
& Male & Female & Total \\
\hline $\begin{array}{l}\text { When was your blood pressure } \\
\text { last measured? }\end{array}$ & & & \\
Within past 12 months & $34(8.5)$ & $25(6.2)$ & $59(14.7)$ \\
1-5 years & $21(5.2)$ & $15(3.7)$ & $36(9.0)$ \\
$\quad$ Not within past 5 years & $215(67.3)$ & $91(22.7)$ & $306(76.3)$ \\
$\begin{array}{l}\text { Do you know that your blood } \\
\text { pressure is raised or not? }\end{array}$ & & & \\
$\quad$ Yes & $9(2.2)$ & $8(2.0)$ & $17(4.2)$ \\
No & $256(63.8)$ & $116(28.9)$ & $372(92.8)$ \\
Uncertain & $5(1.2)$ & $7(1.7)$ & $12(3.0)$ \\
Are you currently taking & & & \\
antihypertensive drugs? & & & \\
$\quad$ Yes & $7(1.7)$ & $4(1.0)$ & $11(2.7)$ \\
No & $263(65.6)$ & $127(31.7)$ & $390(97.3)$ \\
$\begin{array}{l}\text { Do you know that you have } \\
\text { diabetes? }\end{array}$ & & & \\
Yes & $5(1.2)$ & - & $5(1.2)$ \\
No & $258(64.3)$ & $128(31.9)$ & $386(96.3)$ \\
Uncertain & $7(1.7)$ & $3(0.7)$ & $10(2.5)$ \\
\hline
\end{tabular}

significance is more predominant in DBP. However, there is significant increase in blood pressure with age among females (Figure 4). The significance is highly appreciable in SBP.

\section{Discussion}

Globally nearly 140 million people reside at high altitude, defined as elevations above $2500 \mathrm{~m}$ (8000 ft.) [17]. Though global distribution of people at high altitude is a small fraction in some countries a sizeable proportion of population live and reproduce at high altitude. In Himachal Pradesh, India, 30\% of the population resides at high altitude [18].

High altitude environment poses distinct challenges to highlanders and consequent developmental and genetic adaptations are instances of evolutionary modifications required to survive there. Hypoxia is the fundamental adaptive challenge at high altitude and extensive impact on respiratory and cardiovascular system including systemic blood pressure is expected. The extent to which myriad of cardiovascular adaptations affects systemic blood pressure is controversial. Interpretation of information from high altitude residents is influenced by many factors including the altitude of residence, the physical activity patterns of the subjects, and the possible role of genetic changes that may have resulted in advantageous physiological adaptations to a low oxygen environment. There are few populationbased studies examining the effects of chronic exposure to high altitude on systemic blood pressure. Earlier studies established that people who reside at higher altitudes for 

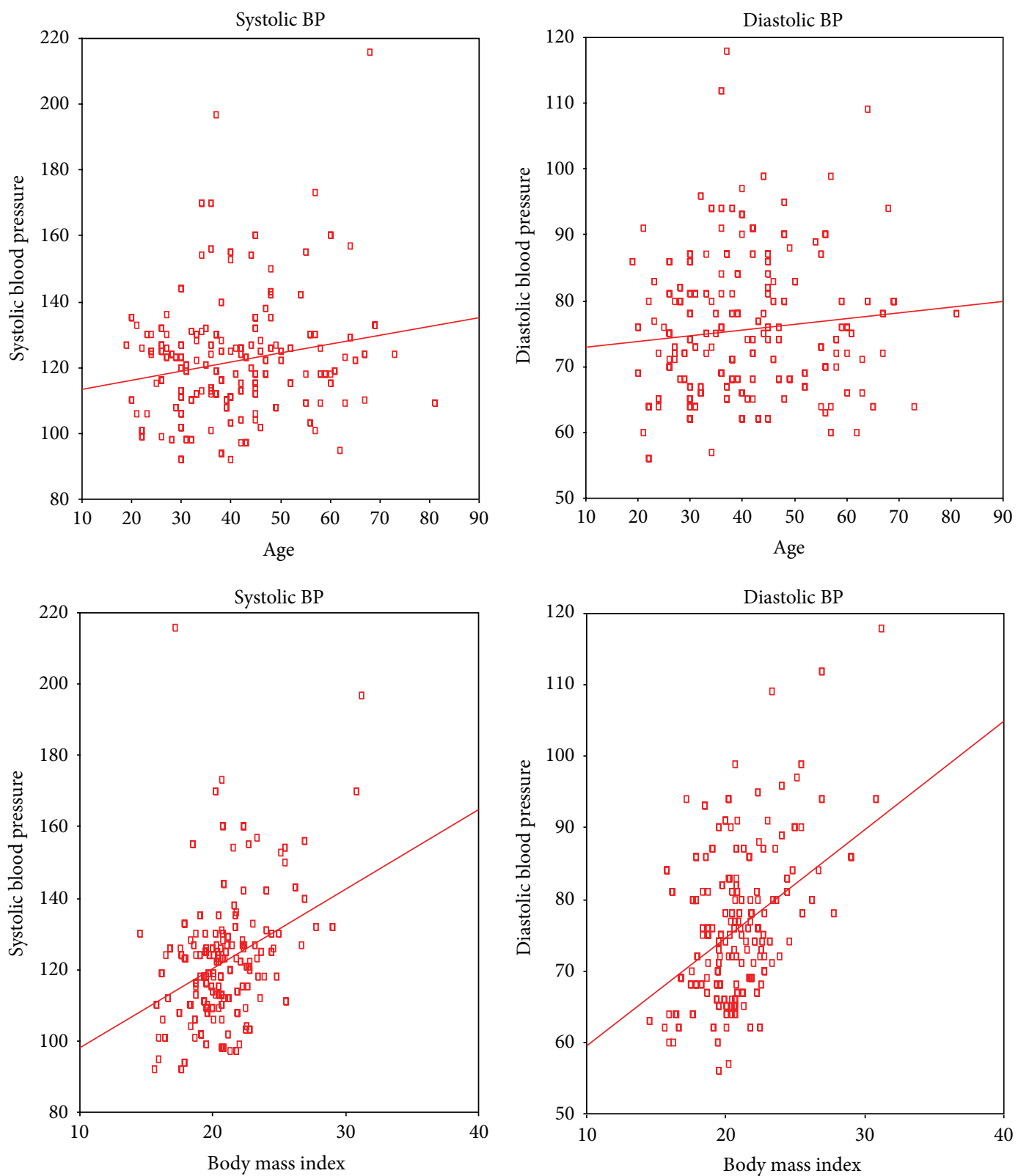

FIGURE 1: Corelation of blood pressure with age and body mass index (BMI). Systolic BP and age (Pearson correlation: 0.196; significance (2 tailed): $\leq 0.001$ ). Diastolic BP and age (Pearson correlation: 0.105; significance (2 tailed): 0.035). Systolic BP and BMI (Pearson correlation: 0.349; significance (2 tailed): $\leq 0.001$ ). Diastolic BP and BMI (Pearson correlation: 0.397; significance (2 tailed): $\leq 0.001)$.

several years apparently have a decrease in both systemic systolic and diastolic pressure $[19,20]$. However, various studies on prevalence of hypertension among natives at high altitudes had conflicting results [2-14]. A study done in Andean highlanders living at $4300 \mathrm{~m}$ above the sea level showed a low prevalence of high blood pressure [5]. However, more recent studies done in Tibetan and Andean highlanders suggest that the prevalence of hypertension is similar or higher than in people living at the sea level $[9,14]$.

The present population-based cross-sectional study was conducted to determine the prevalence of hypertension in a tribal land locked population at high altitude. The study population belongs to an ethnically homogenous population of natives of Pangi valley residing at an altitude of 3048 meters to 3658 meters.

Analysis of the results revealed that overall prevalence of hypertension was $10.7 \%$. The prevalence of hypertension at $10.7 \%$ is much lower than the prevalence reported (36\%) for mainland Himachal Pradesh [21]. The prevalence is also lower than the one reported $(22.5 \%)$ in the recent past by other investigators from high altitude Himachal Pradesh [1]. However, prevalence is higher than one earlier study at high altitude populations which reported a prevalence of only $2 \%$ [10]. Although this could be attributed to the cut-off of 

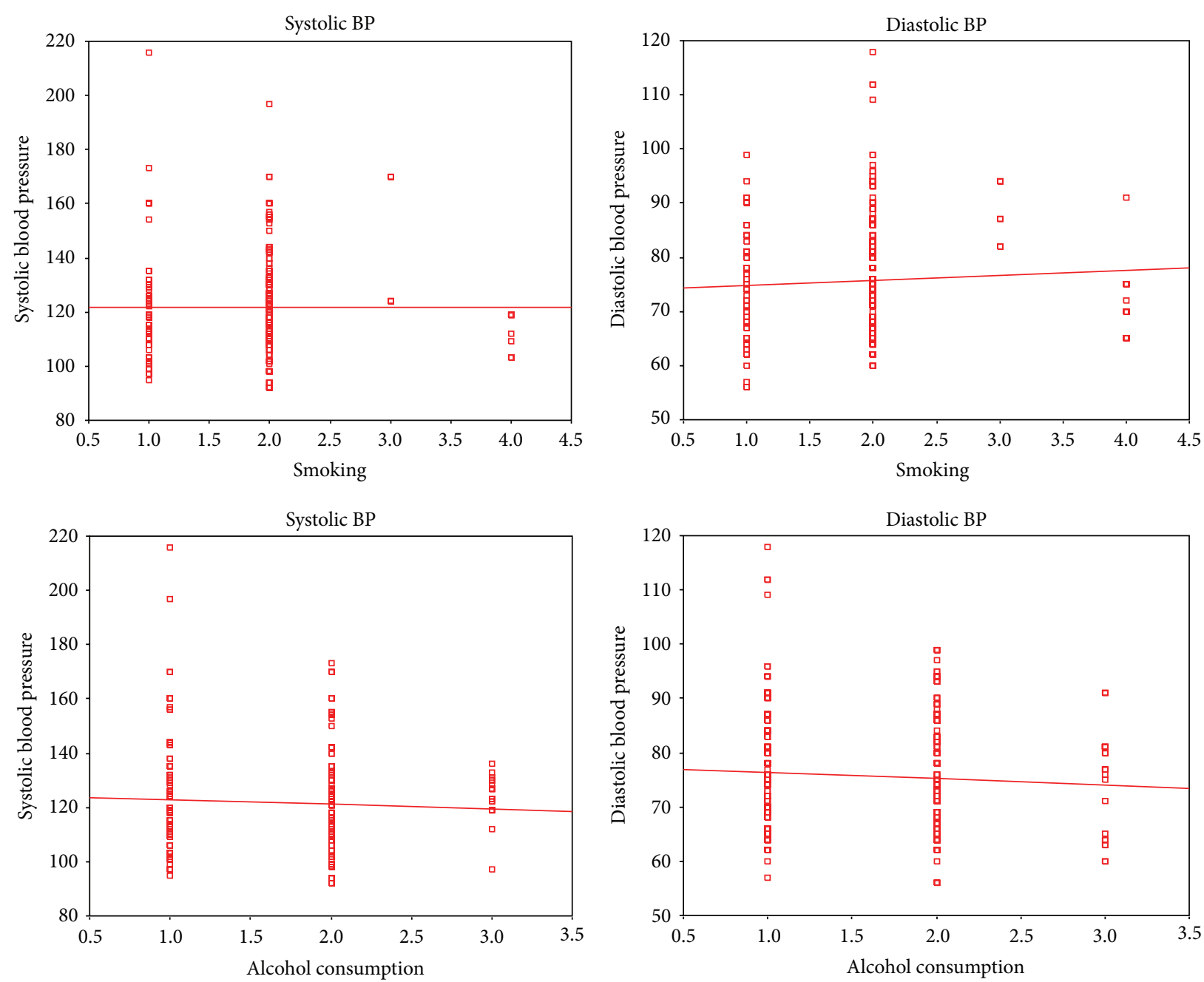

FIGURE 2: Corelation of blood pressure with smoking and alcohol. Systolic BP and smoking (Pearson correlation: -0.002 ; significance (2 tailed): 0.966). Diastolic BP and smoking (Pearson correlation: 0.059; significance (2 tailed): 0.240). Systolic BP and alcohol consumption (Pearson correlation: -0.062 ; significance (2 tailed): 0.218 ). Diastolic BP and alcohol consumption (Pearson correlation: -0.068 ; significance (2 tailed): 0.172).

$160 / 95 \mathrm{~mm}$ of $\mathrm{Hg}$ to diagnose hypertension used in the earlier study. Therefore, it is likely that this has underestimated the true prevalence of hypertension in high altitude natives, which could otherwise have been significant.

Importantly there is no correlation between advancing age and diastolic blood pressure [10]. This constancy of blood pressure with age has also been reported from Easter Island [22] in a community living the traditional way of life. However, systolic blood pressure seems to rise with advancing age. The rise in systolic blood pressure with age is more appreciable in female than male participants.

The prevalence of obesity and diabetes is less in the higher altitude population; this suggests the likely differences in the level of physical activity which is also substantiated by the fact that group 2 is constituted by more farmers. The higher physical activity index may have protective effect independent of BMI which needs to be explored before concluding the protective effects of hypobaric hypoxia induced vascular adapted responses as a mechanism for lower prevalence of hypertension. There appears to be a dichotomy, in which hypertension at lower altitudes is associated more with obesity and classical cardiovascular risk factors, whereas at high altitude the frequency of hypertension correlates more with the presence of polycythemia and hyperuricemia [23]. Studies from different parts of world, conducted in different populations have also shown association of urbanisation, increase in age, socioeconomic status, waist circumference, and BMI with increase in the prevalence of hypertension [2430].

\section{Conclusions}

The overall prevalence of $10.5 \%$ is noteworthy when interpreted in light of prevalence of hypertension in general population especially if hypobaric hypoxia is considered to have a protective effect on blood pressure in high altitude native populations. 

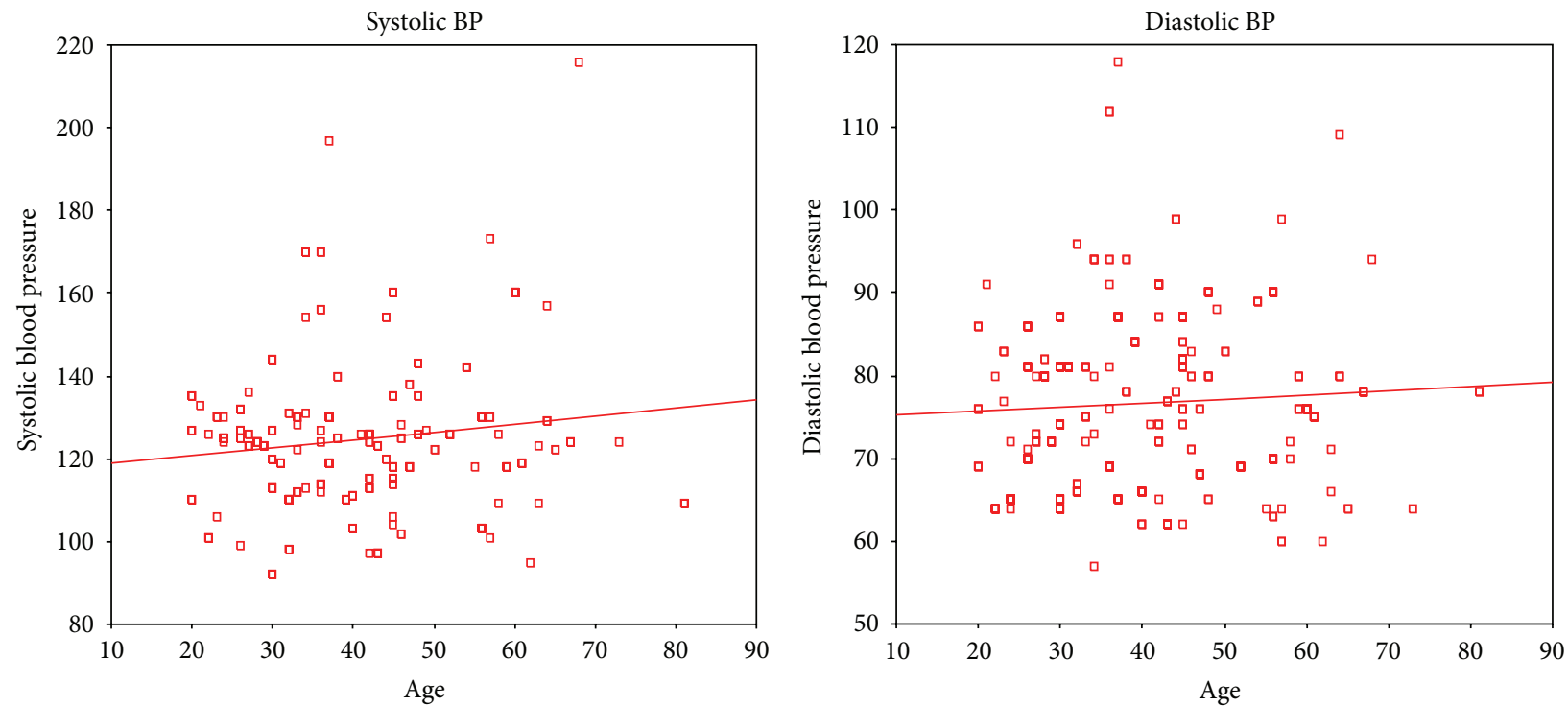

FIGURE 3: Corelation of blood pressure with age among male participants. Systolic BP and age (Pearson correlation: 0.138; significance (2 tailed): 0.023). Diastolic BP and age (Pearson correlation: 0.059: significance (2 tailed): 0.333).
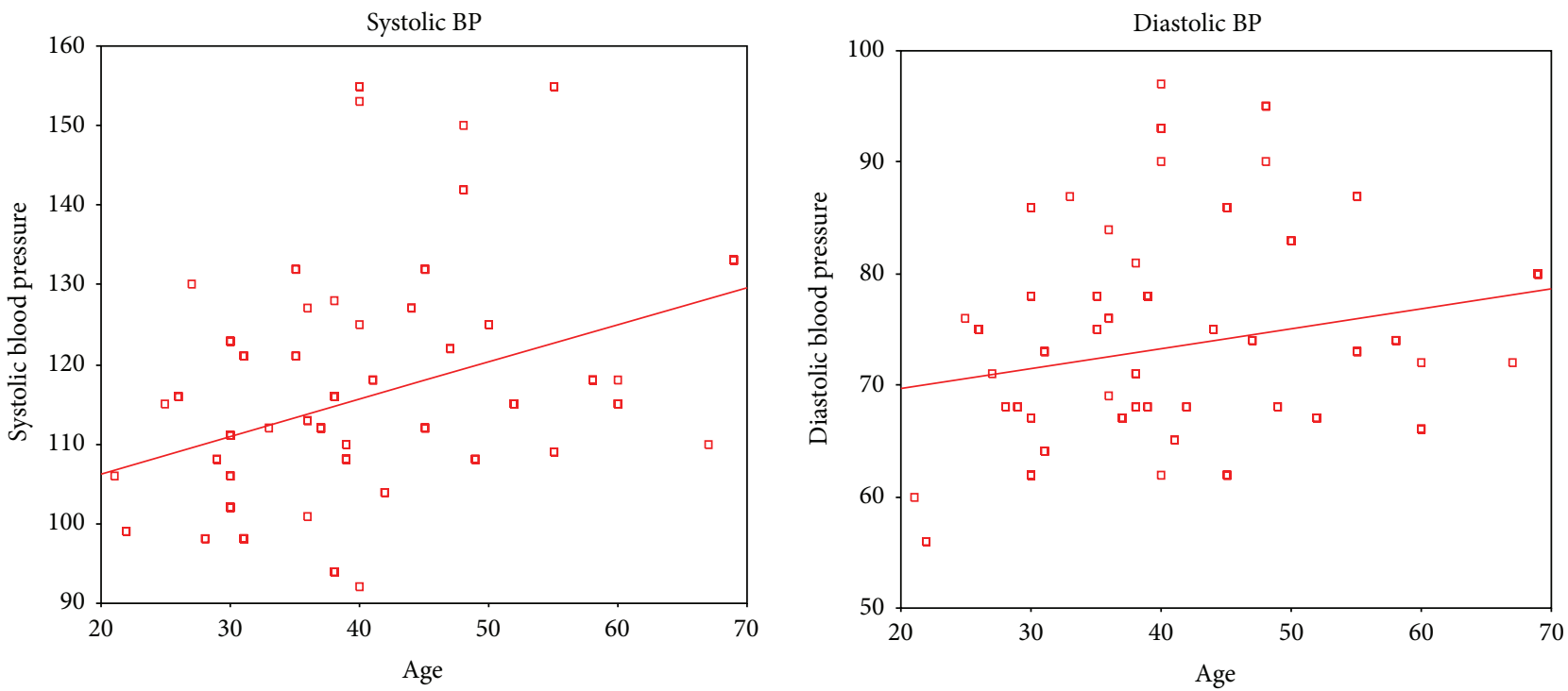

FIGURE 4: Corelation of blood pressure with age among female participants. Systolic BP and age (Pearson correlation: 0.388 ; significance (2 tailed): $<0.001$ ). Diastolic BP and age (Pearson correlation: 0.238; significance (2 tailed): 0.006 ).

\section{Conflict of Interests}

The authors declare that there is no conflict of interests regarding the publication of this paper.

\section{References}

[1] P. C. Negi, R. Bhardwaj, A. Kandoria et al., "Epidemiological study of hypertension in natives of Spiti valley in Himalayas and impact of hypobaric hypoxemia; a cross-sectional study," Journal of Association of Physicians of India, vol. 60, no. 6, pp. 21-25, 2012.
[2] J. L. Rupert and P. W. Hochachka, "The evidence for hereditary factors contributing to high altitude adaptation in Andean natives: a review," High Altitude Medicine and Biology, vol. 2, no. 2, pp. 235-256, 2001.

[3] J. M. Hanna, "Climate, altitude, and blood pressure," Human Biology, vol. 71, no. 4, pp. 553-582, 1999.

[4] M. A. Little, "Human populations in the Andes: the human science basis for research planning," Mountain Research and Development, vol. 1, no. 2, pp. 145-170, 1981.

[5] L. Ruiz and D. Penaloza, "Altitude and hypertension," Mayo Clinic Proceedings, vol. 52, no. 7, pp. 442-445, 1977. 
[6] C. M. Beall, A. Gebremedhin, G. M. Brittenham, M. J. Decker, and M. Shamebo, "Blood pressure variation among Ethiopians on the Simien Plateau," Annals of Human Biology, vol. 24, no. 4, pp. 333-342, 1997.

[7] M. M. Mirrakhimov, Z. S. Rafibekova, A. S. Dzhumagulova, T. S. Meimanaliev, T. M. Murataliev, and K. K. Shatemirova, "Prevalence and clinical peculiarities of essential hypertension in a population living at high altitude," Cor et Vasa, vol. 27, no. 1, pp. 23-28, 1985.

[8] A. Basu, R. Gupta, P. Mitra, and A. Dewanji, "Variation in resting blood pressure in relation to age, body build and altitude among the Sherpas of the eastern Himalaya," in Proceedings of the Indian Statistical Institute Golden Jubilee International Conference of Human Genetics and Adaptation, A. Basu and K. C. Malhotra, Eds., vol. 2 of Human Adaptation, Indian Statistical Institute, Kolkata, India, 1984.

[9] V. Tripathy and R. Gupta, "Blood pressure variation among Tibetans at different altitudes," Annals of Human Biology, vol. 34, no. 4, pp. 470-483, 2007.

[10] D. J. Dasgupta, B. S. Prasher, N. K. Vaidya et al., "Blood pressure in a community at high altitude $(3000 \mathrm{~m})$ at Pooh (North India)," Journal of Epidemiology and Community Health, vol. 36, no. 4, pp. 251-255, 1982.

[11] E. J. Clegg, D. L. Jeffries, and G. A. Harrison, "Determinants of blood pressure at high and low altitudes in Ethiopia," Proceedings of the Royal Society of London A, vol. 194, no. 1114, pp. 63-82, 1976.

[12] M. E. M. Khalid, M. E. Ali, M. E. K. Ahmed, and A. O. Elkarib, "Pattern of blood pressures among high and low altitude residents of southern Saudi Arabia," Journal of Human Hypertension, vol. 8, no. 10, pp. 765-769, 1994.

[13] A. Olziikhutag, N. Dondog, and G. Batmunkh, "Arterial pressure in cattle-breeders living in different climatogeographical zones of Mongolia," Kardiologiya, vol. 19, no. 6, pp. 58-62, 1979.

[14] S. F. Sun, "Epidemiology of hypertension on the Tibetan plateau," Human Biology, vol. 58, no. 4, pp. 507-515, 1986.

[15] M. S. Aldenderfer, "Moving up in the world," American Scientist, vol. 91, no. 6, pp. 542-549, 2003.

[16] K. R. Bharti, "The people \& their lifestyle," in Chamba Himalaya, Amazing Land, Unique Culture, K. R. Bharti, Ed., pp. 79-102, Indus Publishing, New Delhi, India, 2001.

[17] M. A. Pasha and J. H. Newman, "High-altitude disorders: pulmonary hypertension: pulmonary vascular disease: the global perspective," Chest, vol. 137, supplement 6, pp. 13S-19S, 2010.

[18] S. Niermeyer, S. Zamudio, and L. G. Moore, "The people," in High Altitude An Exploration of Human Adaptation, T. F. Hornbein and R. B. Schoene, Eds., vol. 161, pp. 43-44, Marcel Dekker, New York, NY, USA, 2001.

[19] E. Marticorena, L. Ruiz, J. Severino, J. Galvez, and D. Peñaloza, "Systemic blood pressure in white men born at sea level: changes after long residence at high altitudes," The American Journal of Cardiology, vol. 23, no. 3, pp. 364-368, 1969.

[20] H. N. Hultgren, "Reduction of systemic arterial blood pressure at high altitude," Advances in Cardiology, vol. 5, pp. 49-55, 1970.

[21] R. Bhardwaj, A. Kandoria, R. Marwah et al., "Prevalence, awareness and control of hypertension in rural communities of Himachal Pradesh," Journal of Association of Physicians of India, vol. 58, no. 7, pp. 423-425, 2010.

[22] R. Cruz-Coke, R. Etcheverry, and R. Nagel, "Influence of migration on blood pressure of Easter Islanders," The Lancet, vol. 283 , no. 7335 , pp. $697-699,1964$.
[23] W. Chen, Q. Liu, H. Wang et al., "Prevalence and risk factors of chronic kidney disease: a population study in the Tibetan population," Nephrology Dialysis Transplantation, vol. 26, no. 5, pp. 1592-1599, 2011.

[24] American Diabetes Association, "Position statement: diagnosis and classification of diabetes mellitus," Diabetes Care, vol. 30, supplement 1, pp. S42-S47, 2007.

[25] I. S. Okosun, R. S. Cooper, C. N. Rotimi, B. Osotimehin, and T. Forrester, "Association of waist circumference with risk of hypertension and type 2 diabetes in Nigerians, Jamaicans, and African-Americans," Diabetes Care, vol. 21, no. 11, pp. 1836-1842, 1998.

[26] P. Poirier, I. Lemieux, P. Mauriège et al., "Impact of waist circumference on the relationship between blood pressure and insulin. The Quebec health survey," Hypertension, vol. 45, no. 3, pp. 363-367, 2005.

[27] S. Yusuf, S. Reddy, S. Ônpuu, and S. Anand, "Global burden of cardiovascular diseases, part I: general considerations, the epidemiologic transition, risk factors, and impact of urbanization," Circulation, vol. 104, no. 22, pp. 2746-2753, 2001.

[28] S. Yusuf, S. Reddy, S. Ônpuu, and S. Anand, "Global burden of cardiovascular diseases. Part I. General considerations, the epidemiologic transition, risk factors, and impact of urbanization," Circulation, vol. 104, no. 22, pp. 2746-2753, 2001.

[29] S. M. Haffner, H. Miettinen, S. P. Gaskill, and M. P. Stern, "Metabolic precursors of hypertension. The San Antonio Heart Study," Archives of Internal Medicine, vol. 156, no. 17, pp. 19942001, 1996.

[30] S. S. Franklin, W. Gustin IV, N. D. Wong et al., "Hemodynamic patterns of age-related changes in blood pressure: the Framingham heart study," Circulation, vol. 96, no. 1, pp. 308-315, 1997. 


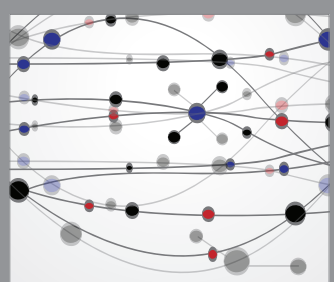

The Scientific World Journal
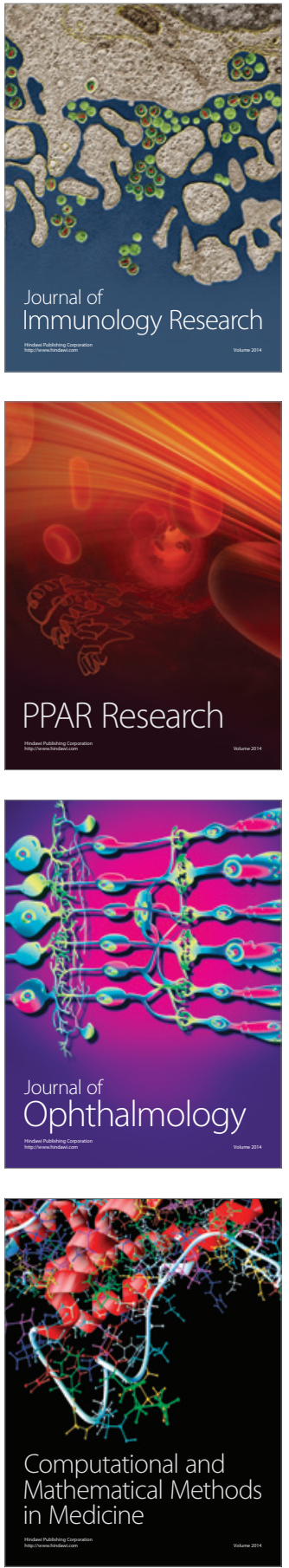

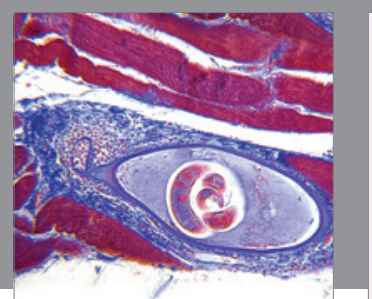

Gastroenterology Research and Practice

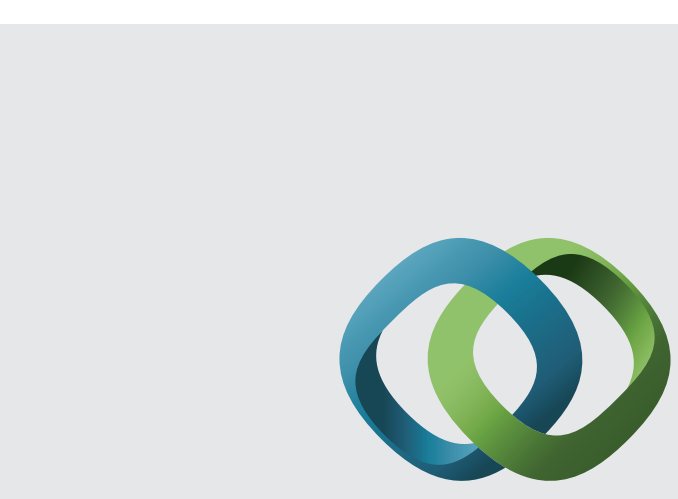

\section{Hindawi}

Submit your manuscripts at

http://www.hindawi.com
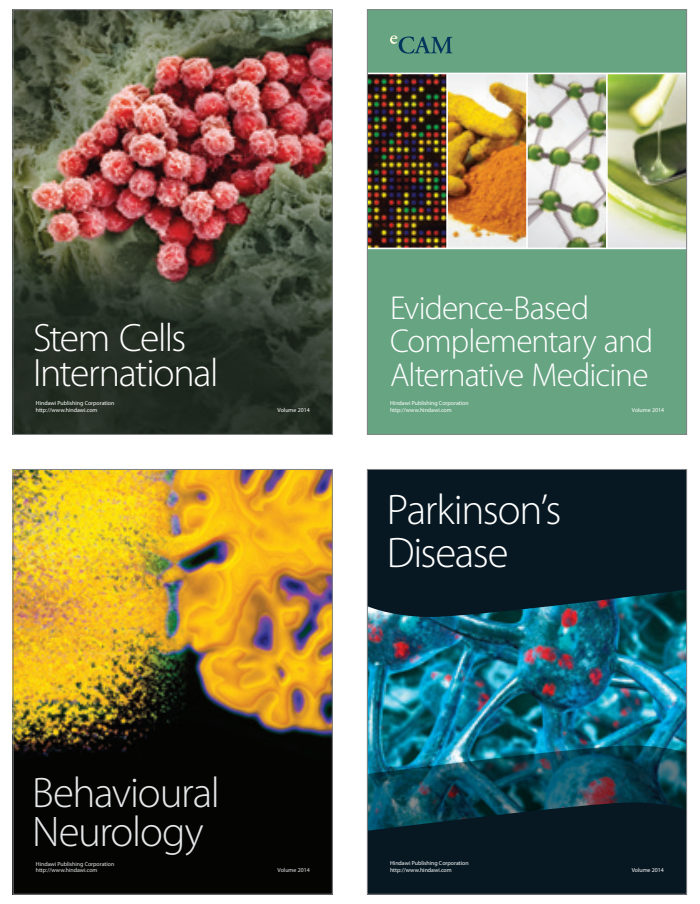
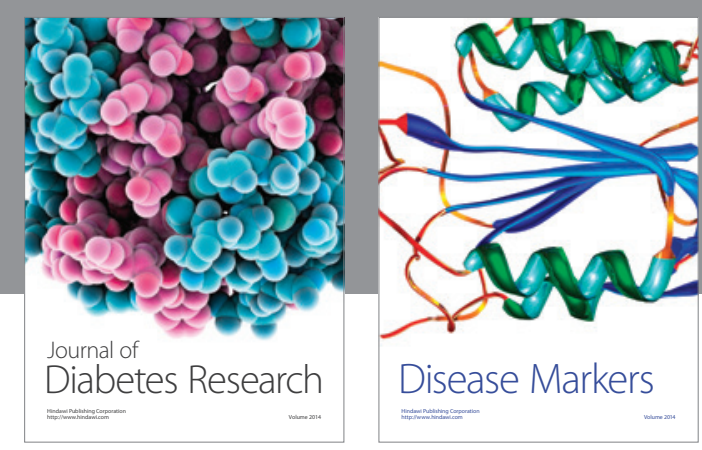

Disease Markers
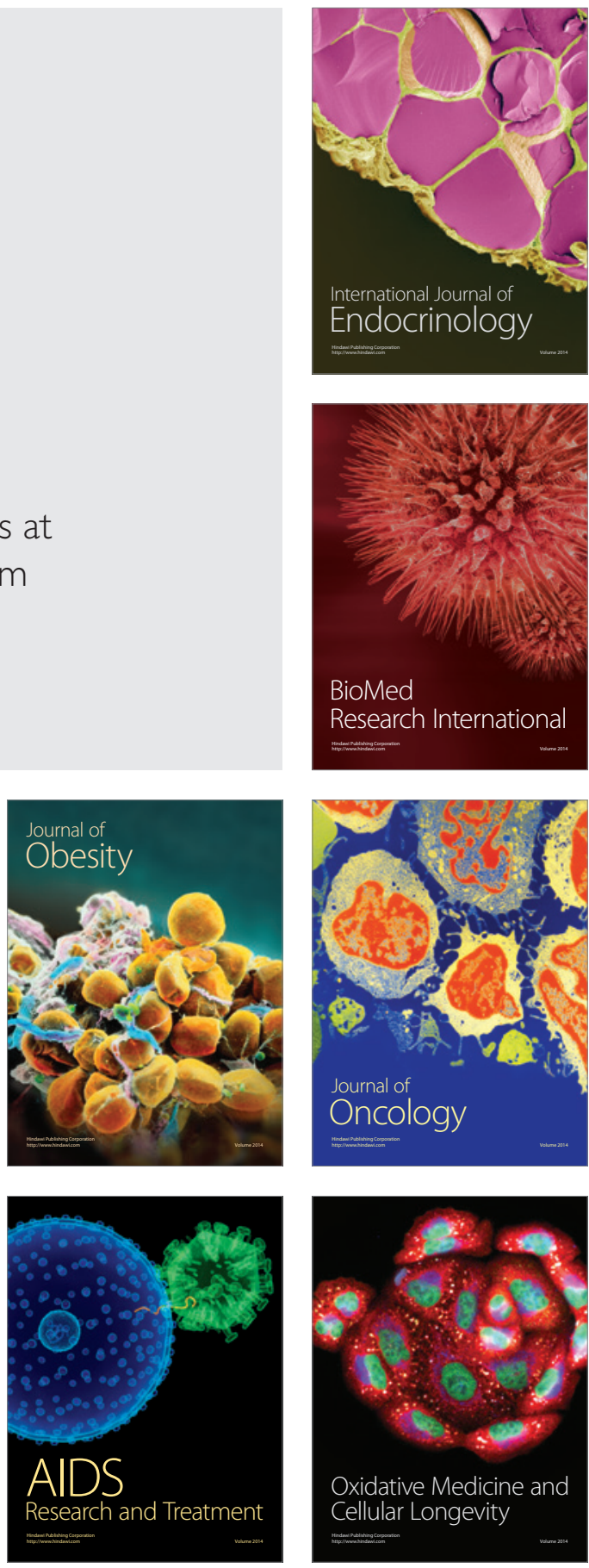